\title{
Low Temperature Direct Bonding between PEEK (Polyetheretherketone) and Pt via Vapor-Assisted Vacuum Ultraviolet Surface Modification
}

\author{
Weixin $\mathrm{Fu}^{1}$, Akitsu Shigetou ${ }^{2}$, Shuichi Shoji ${ }^{1}$ and Jun Mizuno ${ }^{1,3}$ \\ 1. Department of Nanoscience and Nanoengineering, Waseda University, 3-4-1 Okubo Shinjuku-ku, Tokyo 169-8555, Japan \\ 2. National Institute for Material Science (NIMS), 1-1 Namiki, Tsukuba, Ibaraki 305-0044, Japan \\ 3. Institute for Nanoscience and Nanotechnology, Waseda University, 513 Tsurumaki-cho Shinjuku-ku, Tokyo 162-0041, Japan
}

\begin{abstract}
Direct bonding between PEEK (polyetheretherketone) and Pt was achieved at $150{ }^{\circ} \mathrm{C}$ via a vapor-assisted VUV (vacuum ultraviolet) surface modification method. X-ray photoelectron spectroscopy confirmed that the PEEK and Pt outer surfaces were modified with hydrate bridge layers. A model calculation of gas content during VUV irradiation suggested that the water vapor molar concentration should be optimized to no more than $0.088 \mathrm{~mol} / \mathrm{m}^{3}$. The strain energy release rate calculation indicated that the energy required to debond the PEEK-Pt interface reached $270 \mathrm{mN} / \mathrm{m}$, which was higher than the energy required to break the bulk PEEK (42 $\mathrm{mN} / \mathrm{m}$ ). SEM observation of fractured PEEK-Pt bonding agreed well with the calculation result that the fracture occurred within PEEK substrate. Thus, the PEEK-Pt bonding was considered strong enough. This technology is expected to be applied in biomedical MEMS applications.
\end{abstract}

Key words: Vapor-assisted VUV, PEEK, heterogeneous bonding, hydrate bridge layer, surface modification, low-temperature bonding.

\section{Introduction}

Biomedical MEMS (micro-electro-mechanical system) devices have attracted much attention because of their small size, low weight, low power consumption, low cost, and high reliability [1]. Polymers are playing a growing role in biomedical MEMS as packaging materials because of their wide processing versatility [1-5]. The human body is an aqueous environment with particular temperature and chemical corrosion. Thus, biomedical MEMS devices, especially implantable ones, must be durable. PEEK (polyetheretherketone) is a biocompatible thermoplastic polymer with excellent resistance to thermal, chemical, fatigue, moisture, and irradiation degradation [6]. Many studies have suggested PEEK as a replacement for human bones [7, 8]. Therefore,

Corresponding author: Jun MIZUNO, professor, research fields: 3DIC packaging, liquid organic LED, nano-imprint, advanced materials, processes and their application.
PEEK is a suitable alternative for implantable biomedical MEMS packaging materials, such as substrates that contain other devices. PEEK is an insulator; thus, fabricating and packaging electronic components, such as electrodes, on a PEEK substrate requires hybrid bonding between PEEK and metals.

Conventional PEEK-metal bonding is achieved by adhesion $[9,10]$. However, this type of bonding is not intended for biomedical applications. Therefore, there is a risk of toxicity, and adhesion degradation due to the environment in the body may affect device reliability. Furthermore, the complex surface treatment before the adhesive application and the subsequent baking process result in a long turnaround time in MEMS fabrication, increasing the cost. Consequently, direct PEEK-metal bonding is necessary. Welding has been proposed for direct polymer-metal bonding [11]. However, the process temperature is higher than the melting temperature of 
PEEK, which may damage MEMS devices and cause severe problems via differential thermal expansion. Hence, a low-temperature process is required for direct bonding. To realize low-temperature direct PEEK-metal bonding, bondable surfaces must be created on both PEEK and the metal. In addition, the surface activation method should be compatible with PEEK and the metal surface to simplify the fabrication process.

In our previous work, we showed that VUV (vacuum ultraviolet) irradiation eliminated the initial surface organic contamination and created hydrate bridge layers $[12,13]$. The hydrate bridge layers were formed by residual water molecule absorption after the VUV irradiation, and they helped to bond diverse materials tightly through a dehydration reaction [13]. The surface modification method was compatible with PEEK and metals. Furthermore, the quality of the hydrate bridge layers was considered to be controlled by adjusting the water molecule density in the VUV chamber. In our previous work, we used $\mathrm{Pt}$, which is often used as an interconnection metal [14], because it is bioinert and suitable for biomedical applications [15].

In this paper, we propose a low-temperature direct PEEK-Pt bonding method via vapor-assisted VUV surface modification. We focus on the surface modification of vapor-assisted VUV. Five modification conditions were used on the PEEK surface and three conditions on the Pt surface. The changes in atomic concentration and chemical binding after vapor-assisted VUV were analyzed by XPS (X-ray photoelectron spectroscopy). Furthermore, the hydrate bridge layer structure was also discussed based on the XPS data. A shear test was introduced to evaluate bonding strengths between PEEK and Pt, and their strain energy release rate was discussed. The fracturing was observed by SEM (scanning electron microscopy).

\section{Experimental}

\subsection{Sample Preparation}

Pt substrates $(\geq 99.5 \% ; 10 \times 10 \mathrm{~mm}, 0.3 \mathrm{~mm}$ thick) and PEEK substrates $(10 \times 10 \mathrm{~mm}, 0.5 \mathrm{~mm})$ were polished with a Si-C polishing sheet to ensure a uniform initial surface morphology. The substrates were cleaned by successive ultrasonication in acetone, methanol, and pure water (Table 1), although acetone was not used to clean PEEK because of the possibility of damaging the surface and increasing the roughness. The substrates were placed in our vacuum bonding system, which also contained the surface activation equipment and XPS analysis equipment.

\subsection{Bonding Apparatus}

The vacuum bonding system is shown in Fig. 1. The system consisted of a surface activation chamber, a standby chamber, a transfer chamber, an analysis chamber, and a flip chip bonding chamber. Each chamber had its own vacuum system. The surface activation chamber was equipped with a $172 \mathrm{~nm}$ VUV lamp (Ushio), which was $70 \mathrm{~mm}$ above the substrate surface. Information about the VUV lamp is given in Table 2. An ultrasonic atomizer (made by Hodaka Co.) was connected to the surface activation chamber. This equipment was used to convert liquid water into vapor and introduce the vapor during the VUV process. The standby chamber had a high-vacuum environment of $10^{-7} \mathrm{~Pa}$ in which the surface-activated substrates were stored temporarily. The analysis chamber was equipped with an X-ray photoelectron spectrometer (ESCA 1600, ULVAC-PHI). The X-ray source was $\mathrm{Al} \mathrm{K} \alpha(\hbar v=1,486.6 \mathrm{~V})$, the applied power was $450 \mathrm{~V}$,

Table 1 Ultrasonic organic cleaning recipes for Pt and PEEK substrates.

\begin{tabular}{llll}
\hline Cleaning recipe & Acetone & Methanol & Pure water \\
\hline $\mathrm{Pt}$ & $180 \mathrm{~s}$ & $180 \mathrm{~s}$ & $180 \mathrm{~s}$ \\
$\mathrm{PEEK}$ & Not treated & $180 \mathrm{~s}$ & $180 \mathrm{~s}$ \\
\hline
\end{tabular}


Table 2 Detail information of VUV lamp.

\begin{tabular}{ll}
\hline Lamp source & $\mathrm{Xe}_{2}$ \\
\hline Wavelength & $172 \mathrm{~nm}$ \\
Distance from sample surface & $70 \mathrm{~mm}$ \\
Power & $10 \mathrm{~mW} / \mathrm{cm}^{2}$ \\
Operation temperature & Room temperature (about $\left.20^{\circ} \mathrm{C}\right)$ \\
Pressure (before gas introduction) & $1 \times 10^{-4} \mathrm{~Pa}$ \\
\hline
\end{tabular}



Fig. 1 Schematic image of bonding apparatus.

and the relative angle between the X-ray source and the detector was $45^{\circ}$. The flip chip bonding chamber had a heater on the bottom of the lower sample stage.

\subsection{Processes of Surface Modification and Bonding}

A schematic of the bonding procedure is shown in Fig. 2. The cleaned samples were placed in the surface activation chamber, the chamber was evacuated to $10^{-4}$
$\mathrm{Pa}$, and the vacuum pumps were stopped. $\mathrm{N}_{2}$ and water vapor were introduced into the surface activation chamber successively, in the volumes shown in Table 3, until the pressure reached $-3 \mathrm{kPa}$. VUV irradiation was carried out for $10 \mathrm{~min}$, and the chamber was evacuated to $10^{-4} \mathrm{~Pa}$. The surface-modified substrate was transferred into the flipchip bonding chamber. The substrates were flipchip 
(a)

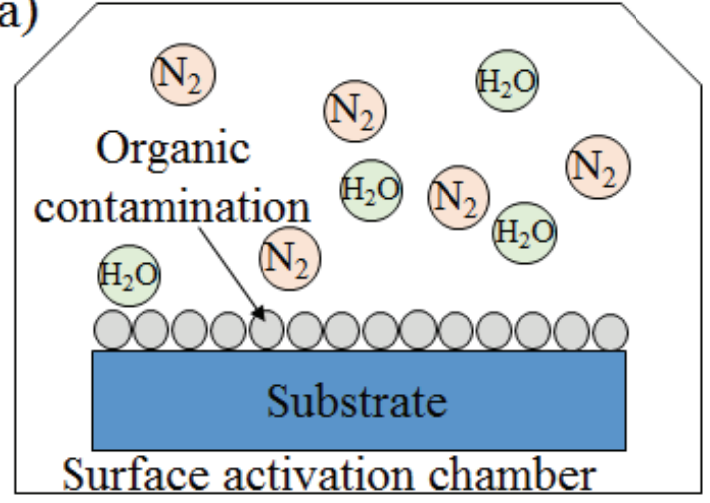

(c)

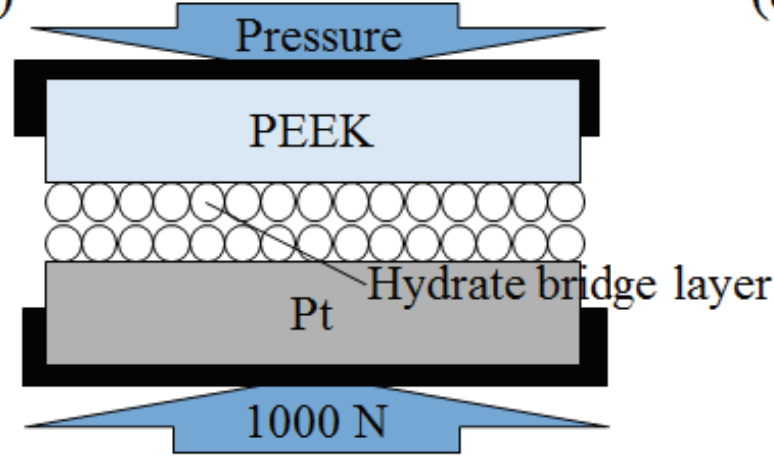

(b)

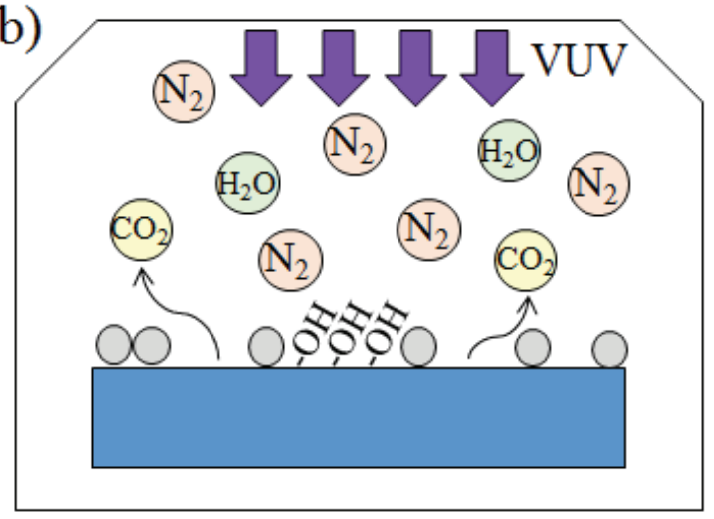

(d)

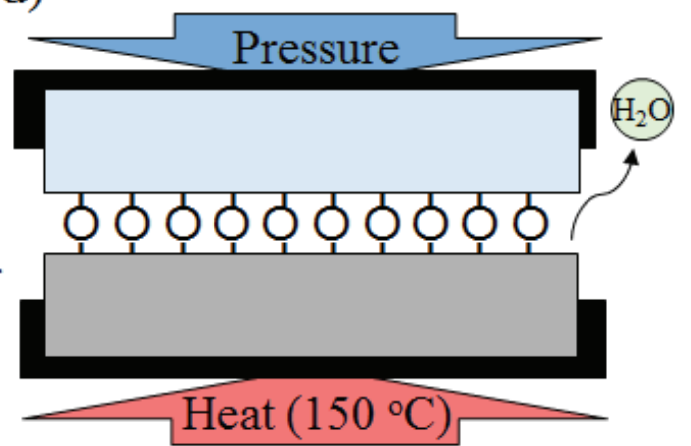

Fig. 2 Outline of bonding process: (a) gas introduction; (b) vapor-assisted VUV modification; (c) flip-chip contact; and (d) heating and dehydration.

Table 3 Gas introduction conditions during vapor-assisted VUV modification.

\begin{tabular}{llll}
\hline Conditions & Gas volume $\left(\mathrm{N}_{2} / \mathrm{H}_{2} \mathrm{O}\right)$ & Water vapor densities & Molar concentrations \\
\hline PEEK 1 & $80 \% / 20 \%$ & $0.11 \mathrm{~g} / \mathrm{m}^{3}$ & $0.006 \mathrm{~mol} / \mathrm{m}^{3}$ \\
PEEK 2 & $70 \% / 30 \%$ & $0.64 \mathrm{~g} / \mathrm{m}^{3}$ & $0.036 \mathrm{~mol} / \mathrm{m}^{3}$ \\
PEEK 3 & $60 \% / 40 \%$ & $1.58 \mathrm{~g} / \mathrm{m}^{3}$ & $0.088 \mathrm{~mol} / \mathrm{m}^{3}$ \\
PEEK 4 & $50 \% / 50 \%$ & $2.98 \mathrm{~g} / \mathrm{m}^{3}$ & $0.165 \mathrm{~mol} / \mathrm{m}^{3}$ \\
PEEK 5 & $10 \% / 90 \%$ & $11.80 \mathrm{~g} / \mathrm{m}^{3}$ & $0.656 \mathrm{~mol} / \mathrm{m}^{3}$ \\
Pt 1 & $70 \% / 30 \%$ & $0.51 \mathrm{~g} / \mathrm{m}^{3}$ & $0.028 \mathrm{~mol} / \mathrm{m}^{3}$ \\
Pt 2 & $50 \% / 50 \%$ & $3.02 \mathrm{~g} / \mathrm{m}^{3}$ & $0.168 \mathrm{~mol} / \mathrm{m}^{3}$ \\
Pt 3 & $10 \% / 90 \%$ & $12.59 \mathrm{~g} / \mathrm{m}^{3}$ & $0.699 \mathrm{~mol} / \mathrm{m}^{3}$ \\
\hline
\end{tabular}

bonded with an applied force of $1,000 \mathrm{~N}$ to ensure good initial contact (PEEK on the top and Pt on the bottom). The substrates were heated to $150{ }^{\circ} \mathrm{C}$, which was near the PEEK glass transition temperature of 140 ${ }^{\circ} \mathrm{C}[16]$, so that the dehydration reaction occurred, and the substrates were kept at $150{ }^{\circ} \mathrm{C}$ for $10 \mathrm{~min}$. In this procedure, the VUV irradiation time and the heating time were set appropriately for our equipment based on its past performance. During the VUV irradiation, the process temperature and relative humidity
(Appendix Table 1) were recorded to calculate water vapor density and molar concentration as

$$
\begin{gathered}
e_{s}(\mathrm{~T})=6.11 \times 10^{\frac{7.5 T}{T+237.3}} \\
a_{s}(\mathrm{~T})=\frac{217 \times e(T)}{T+273.15} \\
a(\mathrm{~T})=a_{s}(T) \times R H \\
C_{\text {Total }}=a(T) \div M_{\text {water }}
\end{gathered}
$$

where, $e_{\mathrm{s}}(t)$ and $a_{\mathrm{s}}(t)$ are saturation water vapor pressure and volumetric humidity (or saturation water 
vapor density), respectively, $a(T)$ is water vapor density in the chamber, $C_{\text {Total }}$ is the total water vapor molecule molar concentration, $R H$ is the relative humidity, and $T$ is the temperature. The calculated water vapor densities and water vapor concentrations are also shown in Table 3.

\subsection{Analysis and Observation Methods}

XPS analysis was performed for both Pt and PEEK substrates before and after VUV irradiation. The spectra were recorded at take-off angles of $15^{\circ}, 30^{\circ}$, and $45^{\circ}$ with respect to the surface normal, corresponding to analysis depths of $0.9,1.7$, and 2.4 $\mathrm{nm}$, respectively, assuming an inelastic mean free path $(\lambda)$ of $3.4 \mathrm{~nm}$ in polymers [17]. The pass energy in our experiment was set at $10 \mathrm{eV}$. The spectrum analysis was performed with MultiPak software (ULVAC-PHI). The spectra backgrounds were removed with Shirley background subtraction for transition metal peaks and linear background subtraction for non-transition metal peaks. The spectra were fitted by using synthetic Gaussian (80\%)-Lorentzian (20\%) components. After bonding, a shear strength test $(4,000$ series bond tester, Nordson) was conducted to evaluate the bonding strain energy release rate between PEEK and Pt. The shear speed was $50 \mu \mathrm{m} / \mathrm{s}$ and the maximum force just before fracture was recorded. In addition, the nominal bonding area was measured with Photoshop (Adobe) during the bonding strength calculation. The fractures were observed by SEM (NB5000, Hitachi).

\section{Results and Discussions}

\subsection{XPS Analysis}

The atomic concentration, core peak, and valence band were determined by XPS after each vapor-assisted VUV modification of PEEK and Pt. In addition, the clean PEEK and Pt substrates were used as references.

3.1.1 Atomic Concentration and Gas Model Calculation

PEEK consists of carbon, oxygen, and hydrogen.
However, only carbon and oxygen were evaluated because it was difficult to quantify the amount of hydrogen directly. The equivalent ratio of the number of $\mathrm{C}$ to $\mathrm{O}$ atoms was used to evaluate the surface modification. The ideal PEEK structure $\left(\left(-\mathrm{O}-\mathrm{C}_{6} \mathrm{H}_{4}-\mathrm{O}-\mathrm{C}_{6} \mathrm{H}_{4}-\mathrm{C}(=\mathrm{O})-\mathrm{C}_{6} \mathrm{H}_{4}-\right)_{\mathrm{n}}\right) \quad$ contains 19 carbon atoms and 3 oxygen atoms per monomeric unit. Thus, the equivalent ratio of the number of $\mathrm{C}$ to $\mathrm{O}$ atoms is 6.33 . The equivalent ratios of the number of $\mathrm{C}$ to $\mathrm{O}$ atoms in vapor-assisted VUV modified PEEK under each set of conditions are shown in Fig. 3 . The curves for the equivalent ratios at $0.9,1.7$, and $2.4 \mathrm{~nm}$ increased with the increase of water vapor density. The lower the equivalent ratio, the more oxygen was contained in PEEK, and thus the more effective the modification was. Hence, the effect of the surface modification decreased as the water vapor density increased because the oxygen content in PEEK decreased. This result was explained by the Beer-Lambert law [18], which states that light attenuation in a material is calculated by

$$
I=I_{0} \mathrm{e}^{-\varepsilon c x}
$$

where, $I_{0}$ is the irradiation intensity of the VUV lamp, $I$ is the irradiation intensity that reached the substrate surface, $\varepsilon$ is the molar attenuation coefficient, $c$ is the material molar concentration, and $x$ is the irradiation distance. The molar attenuation coefficient was estimated as $2.5 \times 10^{7} \mathrm{~cm}^{2} / \mathrm{mol}$ from reference data $[19,20]$. Thus, in our experiment, $I$ was about $0.2 \%$ when the water vapor molar concentration was 0.036 $\mathrm{mol} / \mathrm{m}^{3}$ and 0 when the water vapor molar concentration was $0.088 \mathrm{~mol} / \mathrm{m}^{3}$ or more. This result matched the PEEK curve fitting results, which are discussed in Section 3.1.3. The PEEK chemical binding would not be activated adequately if the photon energy of VUV light was totally consumed to dissociate water vapor molecules; thus, excess water vapor may inhibit the surface modification.

Assuming that the VUV energy absorbed by the water vapor was consumed by water molecule ionization reactions, the $\mathrm{OH}$ - ion concentrations should 


\section{$\mathrm{C} / \mathrm{O}$ ratio}

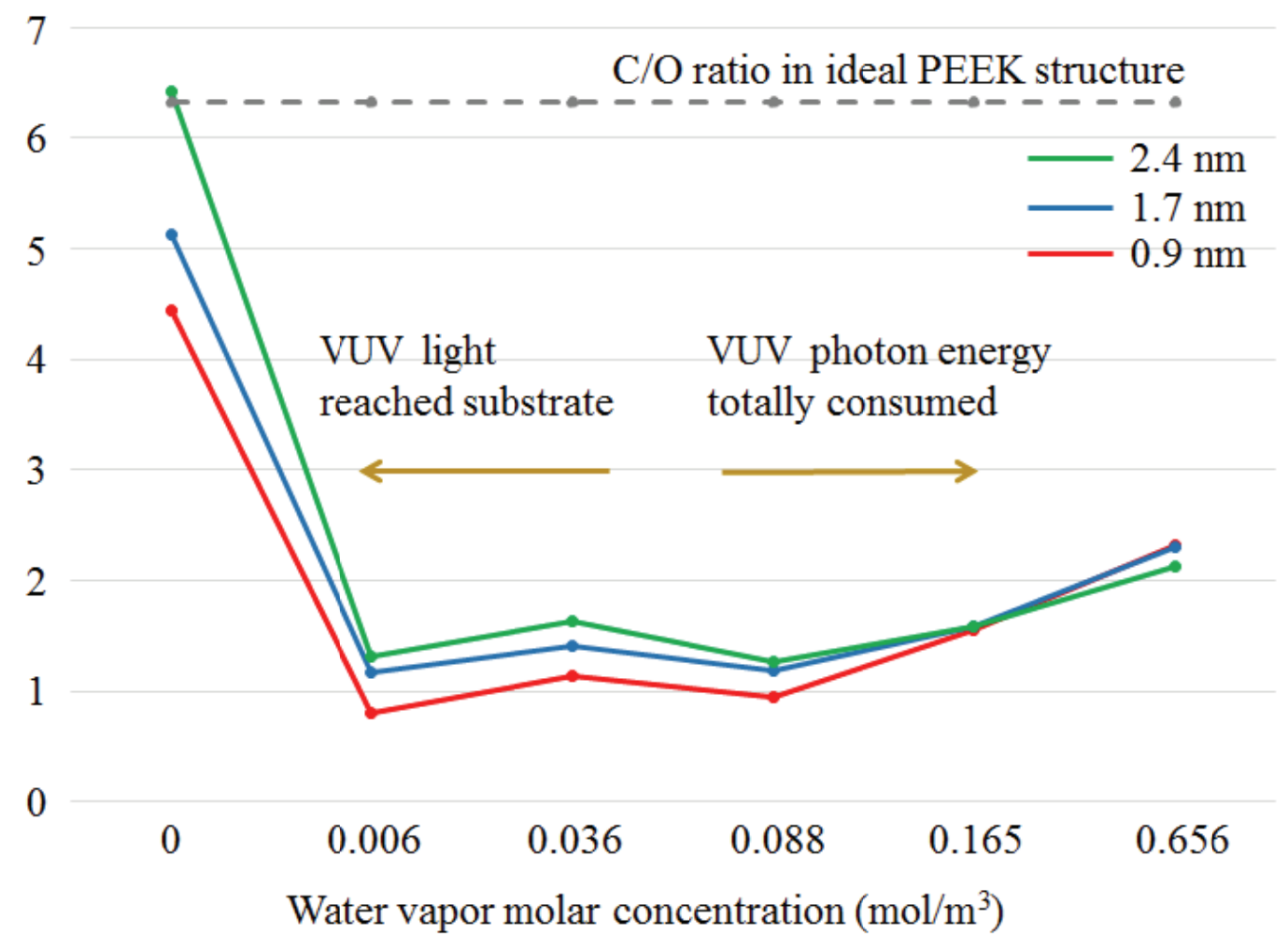

Fig. 3 Diagram of equivalent ratios of atom number for $\mathbf{C}$ to $\mathbf{O}$ corresponding to water vapor molar concentration.

have been the same when the water vapor molar concentration was over $0.088 \mathrm{~mol} / \mathrm{m}^{3}$, because under these conditions all the energy from the VUV lamp was absorbed. However, Fig. 3 shows that the equivalent ratios of the number of $\mathrm{C}$ to $\mathrm{O}$ atoms for the vapor molar concentrations over $0.088 \mathrm{~mol} / \mathrm{m}^{3}$ were different. Thus, the $\mathrm{OH}^{-}$ion concentrations were different under these conditions. To investigate this further, a simple gas model was used, in which the gas molecules and radicals were assumed to disperse uniformly in the chamber and only the following four reactions occurred in the vapor-assisted VUV system.

$$
\begin{gathered}
\mathrm{H}_{2} \mathrm{O}+\hbar v \rightarrow \mathrm{OH}^{-}+\mathrm{H}^{+} \\
\mathrm{OH}^{-}+\hbar v \rightarrow \mathrm{O}\left({ }^{1} \mathrm{D}\right)+\mathrm{H}^{+} \\
\mathrm{O}\left({ }^{1} \mathrm{D}\right)+\mathrm{H}^{+} \rightarrow \mathrm{OH}^{-}+\text {heat } \\
\mathrm{OH}^{-}+\mathrm{H}^{+} \rightarrow \mathrm{H}_{2} \mathrm{O}+\text { heat }
\end{gathered}
$$

The first two reactions may absorb VUV energy, whereas the last two reactions release heat. Assuming that the VUV energies absorbed in the first two equations were the same, we define a coefficient, $p$, which represents the probability that one $\mathrm{H}_{2} \mathrm{O}$ molecule or $\mathrm{OH}^{-}$ion absorbs VUV energy and was activated as $\mathrm{OH}^{-}$or $\mathrm{O}\left({ }^{1} \mathrm{D}\right)$, as

$$
p=\frac{\frac{E_{V U V}}{e}}{\left(c_{O H}+c_{\text {water }}\right) V}
$$

where, $E_{\mathrm{VUV}}$ is the energy absorbed by water vapor, $e$ is the binding energy of the $\mathrm{O}-\mathrm{H}$ bond $(490 \mathrm{~kJ} / \mathrm{mol}), V$ is the chamber volume, and $c_{\mathrm{OH}}$ and $c_{\text {water }}$ are the concentrations of the $\mathrm{OH}^{-}$ions and water vapor molecules in the chamber, respectively. If the VUV energy is completely absorbed by gas, $E_{\mathrm{VUV}}$ is a constant. For a short time, $\Delta t$, Eq. (6) is rewritten as

$$
\begin{aligned}
\mathrm{p}=\frac{W_{V U V} \mathrm{~S} \Delta \mathrm{t}}{e} \frac{1}{\left(c_{O H}+c_{\text {water }}\right) V}= & \frac{W_{V U V}}{e h} \frac{1}{c_{O H}+c_{\text {water }}} \Delta \mathrm{t}= \\
& \alpha \frac{1}{c_{O H}+c_{\text {water }}} \Delta \mathrm{t}
\end{aligned}
$$

where, $W_{\mathrm{VUV}}$ is the power of the VUV source, $S$ is the irradiation area, and $h$ is the distance from the lamp to 
the substrate surface. The result for $W_{\mathrm{vuv}} / e h$ is constant and is converted to coefficient $\alpha$. If we integrate $p$ over a short period of time, $t_{\text {life, }}$, where $t_{\text {life }}$ is defined as the lifetime of $\mathrm{O}\left({ }^{1} \mathrm{D}\right)$, then the concentration of $\mathrm{O}\left({ }^{1} \mathrm{D}\right)$ is calculated by

$$
c_{O 1 D}=\int_{0}^{t_{\text {life }}} \alpha \frac{c_{O H}}{c_{O H}+c_{\text {water }}} d t=\alpha t_{\text {life }} \frac{c_{O H}}{c_{O H}+c_{\text {water }}}(8)
$$

When the gas system is balanced, it fulfills

$$
\begin{array}{r}
\mathrm{p} c_{O H}+\frac{\Delta \mathrm{t}}{V N_{A}} k_{O H} c_{O H}=p c_{\text {water }}+\frac{\Delta \mathrm{t}}{V N_{A}} k_{O 1 D} c_{O 1 D}(9) \quad \begin{array}{l}
\text { molar concentration estimated in } \\
\text { conditions (Table 3). Solving Eq }
\end{array} \\
c_{O 1 D}=\frac{2 \alpha^{3} t_{l i f e^{2} k_{O H}}}{V N_{A}\left[\sqrt{\left(\frac{k_{O H} c_{\text {total }}}{V N_{A}}+2 \alpha-\frac{\alpha t_{\text {life }} k_{O 1 D}}{V N_{A}}\right)^{2}}+\sqrt{\left(\frac{k_{O H} c_{\text {total }}}{V N_{A}}+2 \alpha-\frac{\alpha t_{l i f e} k_{O 1 D}}{V N_{A}}\right)^{2}-4 \frac{\alpha^{2} t_{l i f e} e_{O H}}{V N_{A}}}\right]}
\end{array}
$$

The $\mathrm{O}\left({ }^{1} \mathrm{D}\right)$ concentration, $c_{\mathrm{O} 1 \mathrm{D}}$, is a function of water vapor molar concentration, $c_{\text {total }}$, and $c_{\mathrm{O} 1 \mathrm{D}}$ decreases with the increase of $c_{\text {total }}$. This calculation result matched the observed behavior of the equivalent ratio of the number of $\mathrm{C}$ to $\mathrm{O}$ atoms, which increased with the water vapor density indicating that the modification effect decreased. Therefore, when the water vapor concentration was too high that the VUV photon energy was totally consumed by it, the main mechanism of PEEK surface activation was $\mathrm{O}\left({ }^{1} \mathrm{D}\right)$ attacking the bonds on the PEEK surface.

\subsubsection{PEEK Curve Fitting}

Because bonding between two substrates was dominated by the surface conditions of the substrates, our curve fitting focused on the outer surface $(0.9 \mathrm{~nm})$. A C 1s spectrum of the untreated PEEK outer surface $(0.9 \mathrm{~nm})$ is shown in Fig. 4a for comparison. Figs. 4b-4f show the $\mathrm{C}$ 1s spectra of PEEK outer surfaces modified at water vapor volumes of $20 \%, 30 \%, 40 \%$, $50 \%$, and $90 \%$, respectively. The untreated PEEK surface contained $\mathrm{C}_{\mathrm{x}} \mathrm{H}_{\mathrm{y}}(284.8 \mathrm{eV}$, aromatic [25-28]), C-O (286.6 eV, hydroxyl [25-28]), and $\mathrm{C}=\mathrm{O}(287.7 \mathrm{eV}$, carbonyl [25-28]). After the surface modifications, as shown in Figs. 4b and 4c, aliphatic C-C peaks with an energy gap of $0.8 \pm 0.1 \mathrm{eV}$ appeared [25-28]. These aliphatic bonds were formed from low-molecular-weight materials $[28,29]$, which were formed from the PEEK surface by VUV irradiation. In addition, these $\mathrm{C}-\mathrm{C}$ peaks did not appear when the water vapor concentration was higher than 0.036 $\mathrm{mol} / \mathrm{m}^{3}$. This result matched our calculation (Eq. (5)) that VUV photon energy was totally consumed if the water vapor concentration was higher than 0.036 $\mathrm{mol} / \mathrm{m}^{3}$. In Figs. $4 \mathrm{~b}-4 \mathrm{f}$, the $\mathrm{C}=\mathrm{O}$ peaks were converted into peaks with an energy gap of $4.6 \pm 0.2 \mathrm{eV}$ from the $\mathrm{C}_{\mathrm{x}} \mathrm{H}_{\mathrm{y}}$ peaks and were assigned as carboxylate peaks [25-28]. Since the chamber was filled with $\mathrm{OH}^{-}$ions and there were no other ions adding oxygen into activated carbonyl bond, these carboxylate peaks were $\mathrm{COOH}$ peaks. The $\mathrm{COOH}$ bond was considered to be formed by the $\mathrm{OH}^{-}$ion adsorption to VUV activated carbonyl bond as well as by the singlet oxygen $\mathrm{O}\left({ }^{1} \mathrm{D}\right)$ addition reaction to the aromatic ring [30]. Although hydroxyl functional groups were also formed during the modification, their chemical binding peaks overlapped with C-O peaks from the PEEK structure, and were difficult to identify. The results show that the outer surface of PEEK was modified with carboxyl functional groups.

\subsubsection{Pt Curve Fitting}

The curve fitting result for untreated $\mathrm{Pt}$ is shown in Fig. 5a for comparison. The Pt $4 \mathrm{f}$ spectra curve fitting results for VUV modification at water vapor volumes of $30 \%, 50 \%$, and $90 \%$ are shown in Figs. $5 b-5 d$, respectively. The curve fitting results were for the outer Pt surface to a depth of $0.1 \mathrm{~nm}$ ( $\lambda$ of $0.4 \mathrm{~nm}$ [17]). 

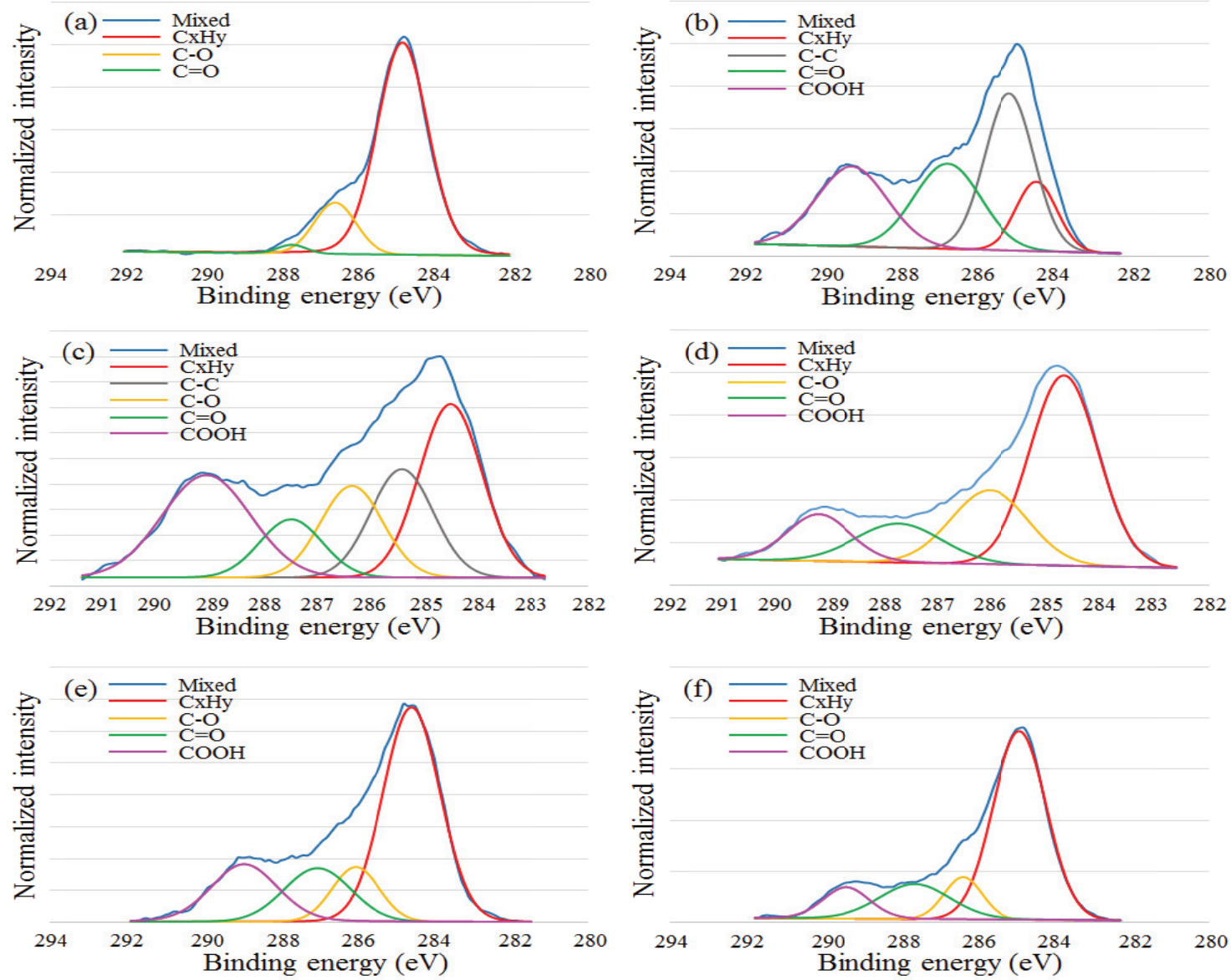

Fig. 4 C 1s spectra curve fitting of PEEK outersurface $(0.9 \mathrm{~nm})$ after vapor-assisted VUV modification of different water vapor volume conditions: (a) untreated (reference); (b) $20 \%$; (c) $30 \%$; (d) $40 \%$; (e) $50 \%$; and (f) $90 \%$.
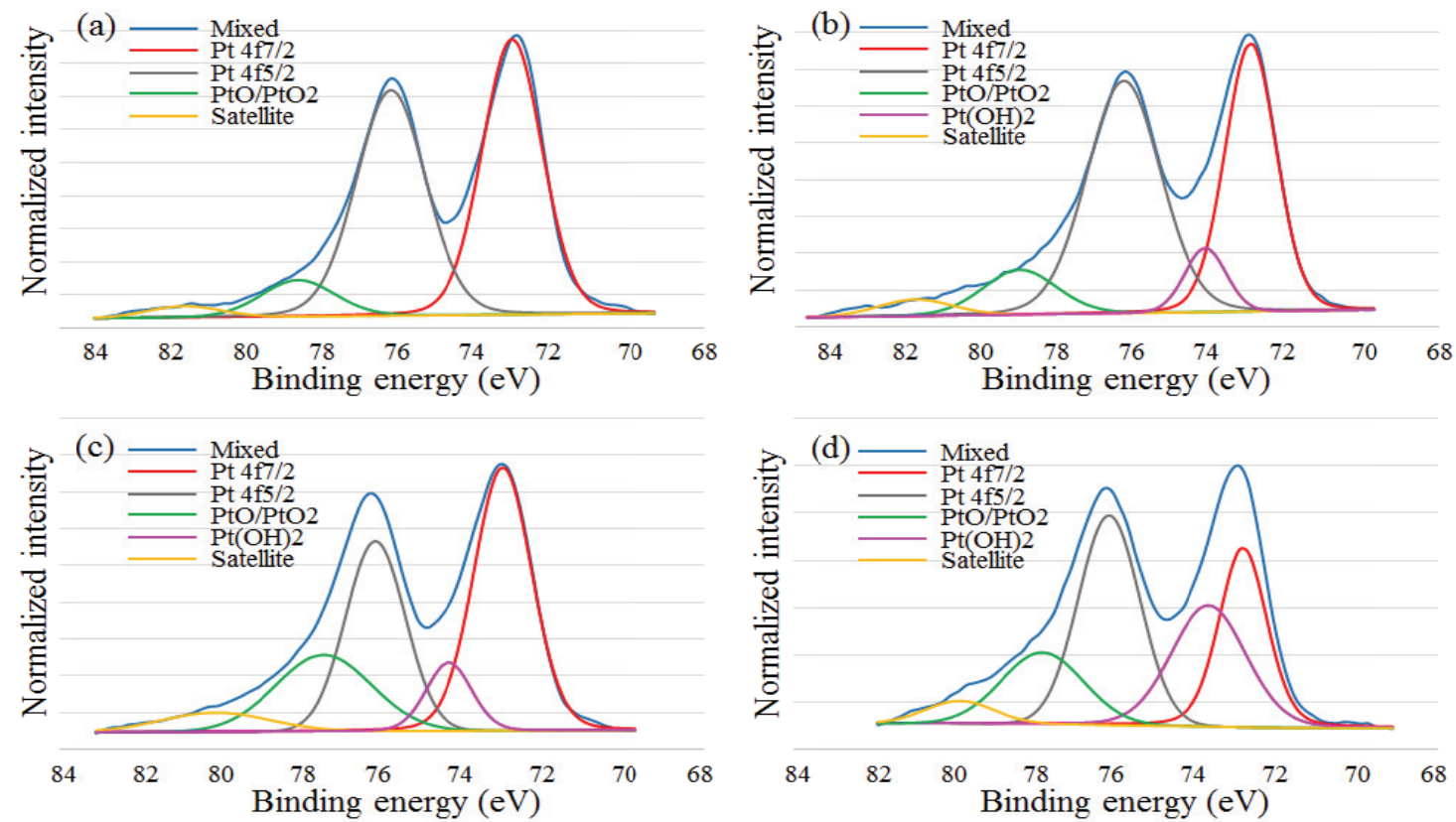

Fig. 5 Pt 4 f spectra curve fitting of Pt outer surface $(0.1 \mathrm{~nm})$ after vapor-assisted VUV modification of different water vapor volume conditions: (a) untreated (reference); (b) $30 \%$; (c) $50 \%$; and (d) $90 \%$. 
In Fig. 5a, the $\mathrm{Pt} 4 \mathrm{f}$ spectrum of the untreated $\mathrm{Pt}$ surface was deconvoluted into two $\mathrm{Pt} 4 \mathrm{f}$ peaks at 71.0 and $74.2 \mathrm{eV}[25,31]$, a PtO peak at $76.7 \mathrm{eV}[25,31]$, and a satellite peak at $79.7 \mathrm{eV}[25,31]$. After the modifications, peaks appeared at $1.1 \pm 0.2 \mathrm{eV}$, matching $\mathrm{PtO}$ and $\mathrm{Pt}(\mathrm{OH})_{2}$ [25, 31]. Because sufficient $\mathrm{OH}^{-}$and $\mathrm{H}^{+}$were present, in which the $\mathrm{H}^{+}$ ions were capable of metal reduction [12], these new peaks were $\mathrm{Pt}(\mathrm{OH})_{2}$ peaks. Therefore, the vapor-assisted VUV method was effective for both PEEK and Pt surface modification.

\subsubsection{Valence Band Analysis}

Normalized valence band curves for PEEK and $\mathrm{Pt}$ are shown in Figs. 6a and 6b. The vapor-assisted VUV modified PEEK curves were the same as the untreated PEEK curve because the valence band from the Fermi level, $E_{\mathrm{F}}(0 \mathrm{eV})$, to about $20 \mathrm{eV}$ contained $\mathrm{C} 2 \mathrm{~s}$ and $\mathrm{C}$ $2 \mathrm{p}$ orbital information [32, 33]. However, increasing tendencies were observed at around $25 \mathrm{eV}$ in all the modified PEEK curves, whereas the untreated PEEK curve decreased. These increasing tendencies were a response to the oxygen increase because the $\mathrm{O} 2 \mathrm{~s}$ peak appears at $30 \mathrm{eV}[32,33]$. The Pt valence band curves are shown in Fig. 6b. The intensity of the states at the Fermi level decreased as the water vapor density increased, which indicated that the number of conductive electrons at the Fermi level decreased. Furthermore, the valence curves above $2 \mathrm{eV}$ showed a horizontal shift to a high binding energy region, which suggested the oxidation of Pt. These shifts were in good agreement with the results in the Section 3.1.3. The oxidation product was $\mathrm{Pt}(\mathrm{OH})_{2}$.

\subsection{Bonding Strength and Interface Strain Energy Release Rate}

Shear tests were performed on samples obtained with $30 \%$ water vapor volume, where VUV irradiation reached the substrate surfaces, and with $90 \%$ water vapor volume, where VUV photon energy was totally consumed by water vapor molecules. The bonding results are summarized in Table 4. The bonding strength of the $30 \%$ water vapor volume sample was higher than that of the $90 \%$ water vapor volume sample. This result agreed well with the surface activation effects estimated by the equivalent ratio of the number of $\mathrm{C}$ to $\mathrm{O}$ atoms (Section 3.1.1).

To evaluate the bonding further, interface strain energy release rate was calculated. It was assumed that the bonded area was a square with a width of $x$ at the center of the bonded materials; cracking only occurred on one side of the square and extended to the opposite side; all the consumed energy during the fracture process was used in cracking, and other energy consumption, such as material deformation, was ignored. The strain energy release rate satisfies [34]

$$
G=-\frac{\partial(U-V)}{\partial A}
$$

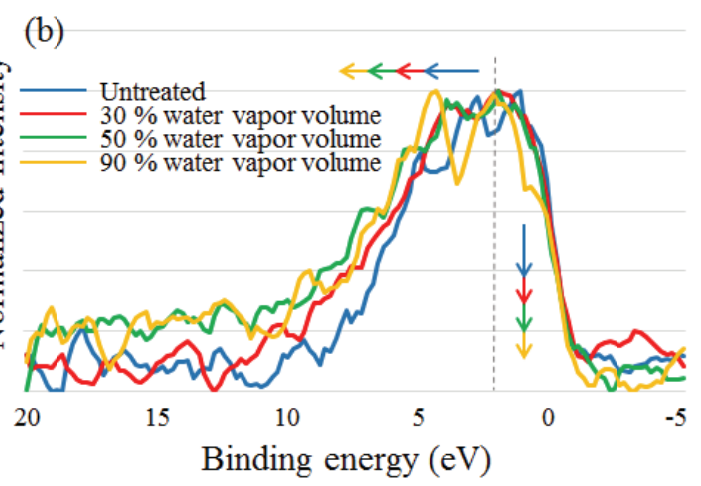

Fig. 6 Valence band analysis on: (a) PEEK (water vapor volume of $20 \%, 30 \%, 40 \%, 50 \%, 90 \%$ and untreated one); and (b) Pt (water vapor volume of $30 \%, 50 \%, 90 \%$ and untreated one). 

Pt via Vapor-Assisted Vacuum Ultraviolet Surface Modification

Table 4 Shear test result, strength calculation and interface strain energy release rate estimation.

\begin{tabular}{|c|c|c|c|c|c|}
\hline Conditions & Sample No. & Fracture force & Nominal bonded area & Bonding strength & $\begin{array}{l}\text { Interface strain energy } \\
\text { release rate }\end{array}$ \\
\hline \multirow{4}{*}{$\begin{array}{l}30 \% \text { water vapor } \\
\text { volume }\end{array}$} & 1 & $628 \mathrm{mN}$ & $5.4 \mathrm{~mm}^{2}$ & $0.12 \mathrm{MPa}$ & $5.0 \times 10^{-3} \mathrm{~N} / \mathrm{m}$ \\
\hline & 2 & $8,774 \mathrm{mN}$ & $8.9 \mathrm{~mm}^{2}$ & $0.99 \mathrm{MPa}$ & $3.4 \times 10^{-1} \mathrm{~N} / \mathrm{m}$ \\
\hline & 3 & $5,750 \mathrm{mN}$ & $5.0 \mathrm{~mm}^{2}$ & $1.15 \mathrm{MPa}$ & $4.6 \times 10^{-1} \mathrm{~N} / \mathrm{m}$ \\
\hline & Average & & & $0.75 \mathrm{MPa}$ & $2.7 \times 10^{-1} \mathrm{~N} / \mathrm{m}$ \\
\hline \multirow{4}{*}{$\begin{array}{l}90 \% \text { water vapor } \\
\text { volume }\end{array}$} & 1 & $1,762 \mathrm{mN}$ & $12.0 \mathrm{~mm}^{2}$ & $0.15 \mathrm{MPa}$ & $7.9 \times 10^{-3} \mathrm{~N} / \mathrm{m}$ \\
\hline & 2 & $4,037 \mathrm{mN}$ & $19.2 \mathrm{~mm}^{2}$ & $0.21 \mathrm{MPa}$ & $1.5 \times 10^{-2} \mathrm{~N} / \mathrm{m}$ \\
\hline & 3 & $1,859 \mathrm{mN}$ & $7.1 \mathrm{~mm}^{2}$ & $0.26 \mathrm{MPa}$ & $2.4 \times 10^{-2} \mathrm{~N} / \mathrm{m}$ \\
\hline & Average & & & $0.21 \mathrm{MPa}$ & $1.6 \times 10^{-2} \mathrm{~N} / \mathrm{m}$ \\
\hline
\end{tabular}

where, $G$ is the strain energy release rate and $A$ is the crack area. Total bonding energy $U$ and work associated with external forces $V$ are calculated [34] by

$$
\begin{aligned}
& \mathrm{U}=\frac{\sigma^{2}}{2 E} x^{2} L \\
& \mathrm{~V}=\frac{\sigma^{2}}{2 E} A L
\end{aligned}
$$

where, $\sigma$ is bonding strength, $E$ is the Young's modulus, and $L$ is the thickness of the substrate. Total bonding energy $U$ is constant; thus, for a homogeneous material, the strain energy release rate can be written as

$$
\mathrm{G}=\frac{\sigma^{2}}{2 E} L
$$

For a heterogeneous material, we take the interface strain energy release rate as the average value of the calculated strain energy release rate from PEEK and Pt for convenience. Hence, the nominal and real interface strain energy release rate is

$$
\begin{gathered}
G_{\text {nominal }}=\frac{\sigma^{2}}{4}\left(\frac{L_{P E E K}}{E_{P E E K}}+\frac{L_{P t}}{E_{P t}}\right) \\
G_{\text {nominal }}=\Omega G_{\text {real }}
\end{gathered}
$$

where, $\Omega$ is the ratio of the real bonded area to the nominal bonded area, which is between 0 and $1 . \Omega$ is estimated to be 0.1 to simplify the calculation. The interface strain energy release rates are summarized in Table 4. For comparison, the surface free energy of PEEK was $42 \mathrm{mN} / \mathrm{m}$. Hence, the bonding for the $90 \%$ water vapor volume sample had an interface strain energy release rate similar to the surface free energy of PEEK. In contrast, the interface strain energy release rate of the bonding for the $30 \%$ water vapor volume sample was approximately 10 times larger than that of the PEEK surface free energy. Thus, the energy required to debond the PEEK-Pt interface was larger than that required to break the bulk PEEK. Therefore, our vapor-assisted VUV modified PEEK-Pt bonding was sufficiently strong.

\subsection{Fractured Substrate Observation}

SEM images were taken of fractured PEEK-Pt bonding from the $30 \%$ water vapor volume sample. Fig. 7a shows the Pt surface after the fracture, and the insets show magnified images of points $\mathrm{A}$ and $\mathrm{B}$ on the surface. The EDX (energy dispersive X-ray) results indicated that a film was present on the $\mathrm{Pt}$ surface. Figs. $7 \mathrm{~b}$ and $7 \mathrm{c}$ show EDX results for Pt_L and $\mathrm{C}_{-} \mathrm{K}$ from the area in Fig. 7a, respectively. Although Pt was present throughout the surface, the area containing the film had a lower Pt density (Fig. 7b), which indicated that the film did not contain Pt. In addition, the surface covered with the film contained carbon, whereas the uncovered area did not (Fig. 7c). Because the Pt surface did not contain carbon, the film material was PEEK bonded to the Pt surface. The observation result indicated that fractures were likely to occur within PEEK bulk than PEEK-Pt interface. Therefore, the bonding interface was stronger than bulk PEEK, which agreed well with the interface strain energy release rates calculated in the last section. 

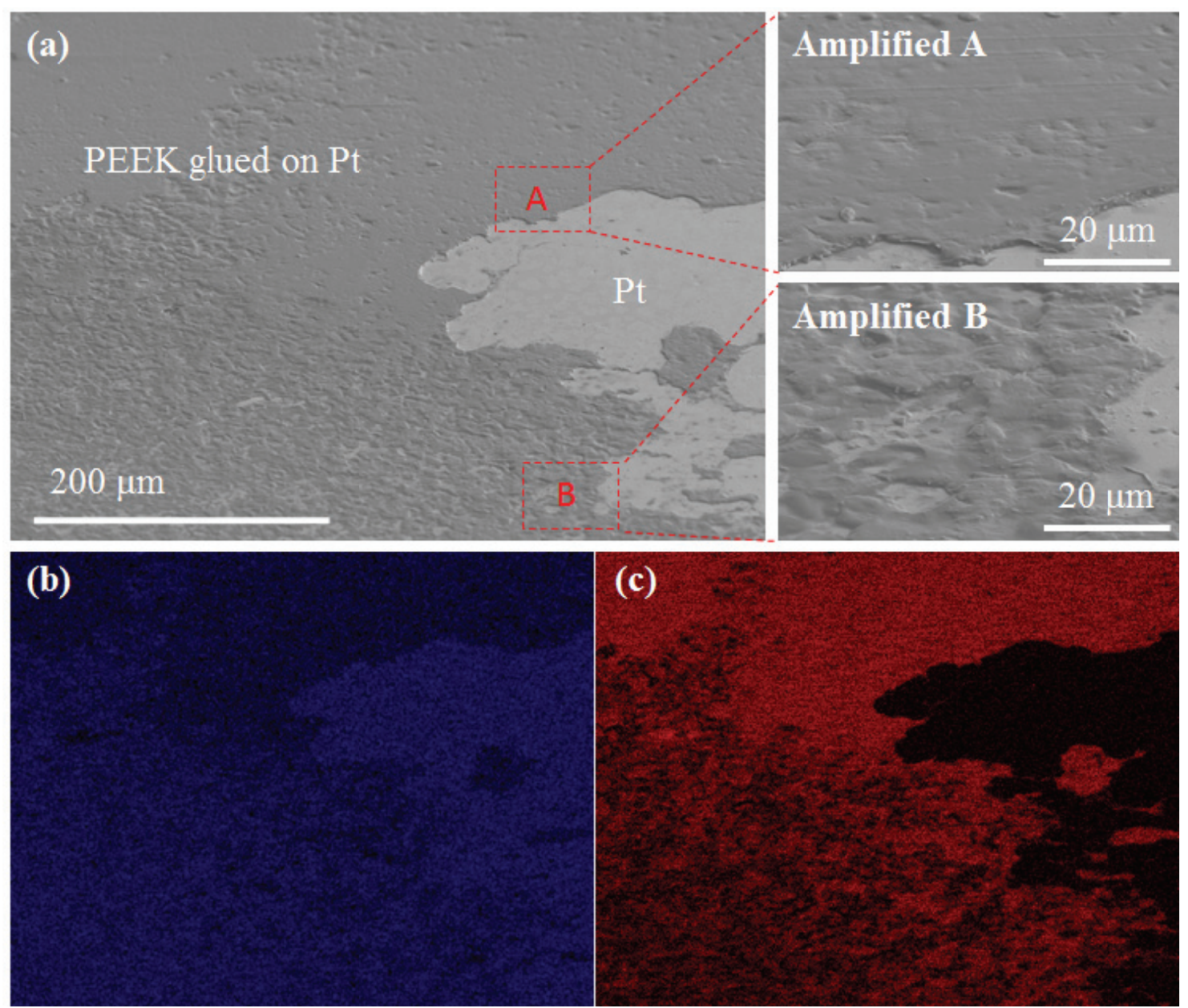

Fig. 7 (a) SEM images of fractured Pt surface (inserted images were amplified images of point A and B); and EXAX analysis results on fractured $\mathrm{Pt}$ (shown in 7a)) of (b) Pt_L, and (c) $\mathrm{C}_{-} \mathrm{K}$.

\section{Conclusions}

The direct heterogeneous bonding between PEEK and $\mathrm{Pt}$ was feasible at $150{ }^{\circ} \mathrm{C}$ via vapor-assisted VUV modification. XPS analyses showed that the surface was modified with hydroxyl bridge layers on the PEEK and Pt surfaces. A model calculation of the gas during the vapor-assisted VUV modification was proposed, and the model suggested that the singlet oxygen $O\left({ }^{1} \mathrm{D}\right)$ density decreased with the increase of water vapor density when the water vapor density was too high that the VUV photon energy was totally consumed. The shear strength test showed that the bonding was sufficiently strong. The calculated interface strain energy release rate indicated that the energy required to debond the PEEK-Pt interface was higher than the energy required to break bulk PEEK. PEEK-Pt bonding is expected to be used in future biomedical MEMS applications. Vapor-assisted VUV modification is a promising alternative for future polymer-metal heterogeneous bonding.

\section{Acknowledgements}

The authors would like to acknowledge Japan Ministry of Education, Culture, Sports, Science and Technology (MEXT) Grantin-Aid for Scientific Basic Research (A) No. $16 \mathrm{H} 02349$ for supporting this work. The authors also wish to acknowledge the support provided by the MEXT Nanotechnology Platform Support Project of Waseda University. And the author $\mathrm{W}$. Fu also acknowledges the Leading Graduate Program in Science and Engineering, Waseda 
University from MEXT, Japan.

\section{References}

[1] Receveur, R. A. M., Lindemans, F. W., and De Rooij, N. F. 2007. "Microsystem Technologies for Implantable Applications." J. Micromech. Microeng. 17: R50-R80.

[2] Thomas, V., Hans, H. R., David, B., Nikos, A., Panagiotis, L., Erik, J., Chantal, K. M., Martin, R., Jürgen, K., and Martin, W. 2005. "Packaging of Bio-MEMS: Strategies, Technologies, and Applications." IEEE Trans. Adv. Pack. 28: 533-46.

[3] Teo., A. J. T., Mishra, A., Park, I., Kim, Y., Park, W. and Yoon, Y. 2016. "Polymeric Biomaterials for Medical Implants and Devices." ACS Biomater. Sci. Eng. 2: 454-72;

[4] Kim, B. J., and Meng, E. 2016. "Review of Polymer MEMS Micromachining.” J. Micromech. Microeng. 26: 013001.

[5] Amanat, N., James, N. L., and McKenzie, D. R. 2010. "Welding Methods for Joining Thermoplastic Polymers for the Hermetic Enclosure of Medical Devices." Med. Eng. Phys. 32: 690-9.

[6] Kim, D. H., Viventi, J., Amsden, J. J., Xiao, J., Vigeland, L., Kim, Y., Blanco, J. A., Panilaitis, B., Frechette, E. S., Contreras, D., Kaplan, D. L., Omenetto, F. G., Huang, Y., Hwang, K., Zakin, M. R., Litt, B., and Rogers, J. A. 2010. "Dissolvable Films of Silk Fibroin for Ultrathin Conformal Bio-Integrated Electronics." Nat. Mater. 9: 511-7.

[7] Kurtz, S. M., and Devine, J. N. 2007. "PEEK Biomaterials in Trauma, Orthopedic, and Spinal Implants." Biomater. 28: 4845-69.

[8] Mano, J. F., Sousa, R. A., Boesel, L. F., Neves, N. M., and Reis, R. L. 2004. "Bioinert, Biodegradable and Injectable Polymeric Matrix Composites for Hard Tissue Replacement: State of Art and Recent Developments." Compos. Sci. Technol. 64: 789-817.

[9] Molitor, P., Barron, V., and Young, T. 2001. "Surface Treatment of Titanium for Adhesive Bonding to Polymeric Composites: a Review." Int. J. Adhes. Adhes. 21: 129-36.

[10] Laurens, P., Sadras, B., Decobert, F., Arefi-Khonsari, and Amouroux, J. 1998. "Enhancement of the Adhesive Bonding Properties of PEEK by Excimer Laser Treatment." Int. J. Adhes. Adhes. 18: 19-27.

[11] Mitschang, P., Velthuis, R., and Didi, M. 2013. "Introduction Spot Welding of Metal/CFRPC Hybrid Joints." Adv. Eng. Mater. 15: 804-13.

[12] Shigetou, A., and Suga, T. 2012. "Vapor-assisted Surface Activation Method for Homo- and Heterogeneous Bonding of $\mathrm{Cu}, \mathrm{SiO}_{2}$ and Polyimide at $150 \mathrm{C}$ and
Atmospheric Pressure.” J. Electron. Mater. 41: 2274-80.

[13] Fu, W., Shigetou, A., Shoji., S., and Mizuno, J. 2017. "Low-temperature Direct Heterogeneous Bonding of Polyether Ether Ketone and Platinum." Mat. Sci. Eng. C 79: 860-5.

[14] He, X., Liu, M., Yang, G., Fan, S., and Li, C. 2011. "Correlation between Microstructure and Property of Electroless Deposited Pt Counter Electrodes on Plastic Substrate for Dye-Sensitized Solar Cells." Appl. Surf. Sci. 258: 1377-84.

[15] Guarnieri, V., Biazi, L., Marchiori, R., and Lago, A. 2014. "Platinum Metallization for MEMS Application." Biomatter 4: e28822.

[16] Shukla, D., Negi, Y. S., Uppadhyaya, J. S., and Kumar, V. 2012. "Synthesis and Modification of Poly (Ether Ether Ketone) and Their Properties: A Review." Polym. Rev. 52: 189-228.

[17] Powell, C. J. 2010. NIST Electron Inelastic-Mean-Free-Path Database, ver. 1.2.

[18] Naganuma, Y., Tanaka, S., Kato, C., and Shindo, T. 2004. "Formation of Silica Coatings from Perhydropolysilazane Using Vacuum Ultraviolet Excimer Lamp.” J. Ceram. Soc. Jpn. 112: 599-603 (in Japanese).

[19] Watanabe, K., and Zelikoff, M. 1953. "Absorption Coefficients of Water Vapor in the Vacuum Ultraviolet." J. Opt. Soc. Am. 43: 753-5.

[20] Watanabe, K., Edward, C., Inn, Y., and Zelikoff, M. 1953. "Absorption Coefficients of Oxygen in the Vacuum Ultraviolet.” J. Chem. Phys. Phys. 21: 1026-30.

[21] Paraskevopoulos, G., and Singleton, D. L. 1988. "Reactions of $\mathrm{OH}$ Radicals with Inorganic Compounds in the Gas Phase." Rev. Chem. Intermed. 10: 139-218.

[22] Wilson Wm., E. Jr. 1972. "A Critical Review of the Gas-Phase Reaction Kinetics of the Hydroxyl Radical." $J$. Phys. Chem. Ref. Data 1: 535-74.

[23] Gericke, K. H., and Comes, F. J. 1981. "Energy Partitioning in the Reaction $\mathrm{O}\left({ }^{1} \mathrm{D}\right)+\mathrm{H}_{2} \mathrm{O} \rightarrow \mathrm{OH}+\mathrm{OH}$. The Influence of $\mathrm{O}\left({ }^{1} \mathrm{D}\right)$ Translational Energy on the Reaction Rate Constant." Chem. Phys. Lett. 81: 218-22.

[24] Biedenkapp, D., Hartshorn, L. G., and Bair, E. J. 1970. "The $\mathrm{O}\left({ }^{1} \mathrm{D}\right)+\mathrm{H}_{2} \mathrm{O}$ Reaction." Chem. Phys. Lett. 5: 379-80.

[25] Moulder, J. F. 1992. Handbook of X-Ray Photoelectron Spectroscopy.

[26] Tien, H. W., Huang, Y. L., Yang, S. Y., Wang, J. Y., and Ma, C. C. M. 2011. "The Production of Graphene Nanosheets Decorated with Silver Nanoparticles for Use In Transparent, Conductive Films." Carbon 49: 1550-60.

[27] Lopez, G. P., Castner, D. G., and Ratner, B. D. 1991. "XPS O 1s Binding Energies for Polymers Containing Hydroxyl, Ether, Ketone, and Ester Groups." Surf 
Interface Anal. 17: 267-72.

[28] Shinohara, H., Kasahara, T., Shoji, S., and Mizuno, J. 2011. "Studies on Low-Temperature Direct Bonding of VUV/O $3^{-}, \quad$ VUV- and $\mathrm{O}_{2} \quad$ Plasma-Pre-Treated Poly-Methylmethacrylate." J. Micromech. Microeng. 21: 085028 (9pp).

[29] Davidson, M. R., Mitchell, S. A., and Bradley, R. H. 2005. "Surface Studies of Low Molecular Weight Photolysis Products from UV-ozone Oxidized Polystyrene." Surf. Sci. 581: 169-77.

[30] Badran, I., Nassar, N. N., Marei, N. N., and Hassan, A. 2016. "Theoretical and Thermogravimetric Study on the Thermo-Oxidative Decomposition of Quinolin-65 as an Asphaltene Model Molecule." RSC $A d v$. 6: 54418-30.
[31] Mathe, N. R., Scriba, M. R., and Coville, N. J. 2014. "Methanol Oxidation Reaction Activity of Microwave-Irradiated and Heat-Treated $\mathrm{Pt} / \mathrm{Co}$ and $\mathrm{Pt} / \mathrm{Ni}$ Nano-Electrocatalysts." Int. J. Hydrogen Energy 39: 18871-81.

[32] Cain, S. R., and Matienzo, L. J. 1992. "Valence Band X-Ray Photoelectron Spectroscopy of Poly (ether ketone) and Poly (ether-ether ketone)." J. Polym. Sci. Pol. Phys. 30: 275-9.

[33] Patel, K., Doyle, C. S., James, B. J., and Hyland, M. M. 2010. "Valence Band XPS and FT-IR Evaluation of Thermal Degradation of HVAF Thermally Sprayed PEEK Coatings.” Polym. Degrad. Stabil. 95: 792-7.

[34] Griffith, A. A. 1920. "The Phenomena of Rupture and Flow in Solids.” Philos. T. Roy. Soc. A 221: 163-98. 

Pt via Vapor-Assisted Vacuum Ultraviolet Surface Modification

\section{Appendix}

Table 1 Gas introduction conditions and the recorded relative humidity, temperature during vapor-assisted VUV modification.

\begin{tabular}{llll}
\hline Conditions & Gas inlet $\left(\mathrm{N}_{2} / \mathrm{H}_{2} \mathrm{O}, \%\right)$ & Relative humidity $(\%)$ & Irradiation temperature $\left({ }^{\circ} \mathrm{C}\right)$ \\
\hline PEEK 1 & $80 / 20$ & 0.60 & 20.55 \\
PEEK 2 & $70 / 30$ & 3.60 & 20.55 \\
PEEK 3 & $60 / 40$ & 8.80 & 20.60 \\
PEEK 4 & $50 / 50$ & 16.60 & 20.60 \\
PEEK 5 & $10 / 90$ & 64.30 & 21.00 \\
Pt 1 & $70 / 30$ & 2.80 & 20.80 \\
Pt 2 & $50 / 50$ & 16.60 & 20.85 \\
Pt 3 & $10 / 90$ & 68.40 & 21.05 \\
\hline
\end{tabular}

